\title{
Effect of Devices and Driving Pressures on Energy Requirements and Mass Transfer Coefficient on Microalgae Lipid Extraction Assisted by Hydrodynamic Cavitation
}

\author{
Martomo Setyawana,b, Panut Mulyono ${ }^{a}$, Sutijana, Yano Surya Pradana ${ }^{a}$, Laras \\ Prasaktia , Arief Budimana,c,* \\ ${ }^{a}$ Chemical Engineering Department, Faculty of Engineering, Universitas Gadjah Mada, Jalan Grafika 2 Yogyakarta, Indonesia \\ ${ }^{b}$ Faculty of Industrial Engineering, Ahmad Dahlan University, Jalan Ahmad Yani, Tamanan, Bantul, Yogyakarta, Indonesia, \\ ${ }^{c}$ Center of Excellence for Microalgae Biorefinery, Universitas Gadjah Mada, Sekip K IA, Yogyakarta, Indonesia
}

\begin{abstract}
Previous studies of biodiesel production from microalgae have concluded that microalgal biodiesel is not profitable at an industrial scale due to its excessive energy consumption for lipid extraction. Hydrodynamic cavitation lipid extraction is one of the extraction methods which has lower energy consumption. This method enables a fast extraction rate and low energy consumption for cell disruption. In order to achieve optimum process conditions, several influential parameters, which are cavitation generator geometry and driving pressure, need to be scrutinized. The experimental result showed that the maximum yield was obtained at 5 bar driving pressure. The lowest specific extraction energy was obtained at 4.167 bar driving pressure while using one side concave cavitation generator geometry with the ratio of the reduced cross-sectional area of 0.39 . The value of the energy extraction requirement $17.79 \mathrm{~kJ} J u l e / g$ lipids is less than the biodiesel heating value, and the value of the volumetric mass transfer coefficient is almost 20 times fold greater than the conventional extraction method, therefore this method is promising to be further developed.
\end{abstract}

Keywords: Hydrodynamic cavitation, lipid extraction, cavitation generator geometry, driving pressure, specific extraction energy

Article History: Received: 28 ${ }^{\text {th }}$ Nov 2019; Revised: $8^{\text {th }}$ July 2020; Accepted: $24^{\text {th }}$ August 2020 ; Available online: $27^{\text {th }}$ August 2020

How to Cite This Article: Setyawan, M., Mulyono, P., Sutijan, Pradana, Y.S., Prasakti, L., and Budiman, A. (2020). Effect of Devices and Driving Pressures on Energy Requirements and Mass Transfer Coefficient on Microalgae Lipid Extraction Assisted by Hydrodynamic Cavitation. Int. Journal of Renewable Energy Development, 9(3), 467-473

https://doi.org/10.14710/ijred.2020.26773

\section{Introduction}

As the world still depends on the unsustainable and depleting non-renewable energy resources, it is mandatory to consider that harnessing renewable energy resources is the best solution to maintain energy security in the future (Budiman and Ishida, 1996; Pradana et al., 2017; Sudibyo et al., 2017). Biomass and vegetable oil are one of the most suitable renewable energy resources for Indonesia. However, the use of these materials as energy resources is also later considered a threat against food and land security (Pradana et al., 2018). Non-edible vegetable oil or waste of biomass are preferred to serve as energy resources to avoid this problem (Suganya et al., 2016). Some researchers had investigated some fuels from nonedible and waste renewable resources, for instance: (i) biooil from palm empty fruit branch (EFB) (Sunarno et al., 2018), wood (Chukwuneke et al., 2019), vegetables and fruit waste (Wicakso et al., 2018), frying oils wastes (Soulayman and Ola, 2019) microalgae (Cheng et al., 2019), microalgae residue (Jamilatun et al., 2019); (ii) biodiesel from palm fatty acid distillate (Sawitri et al.,
2016), jatropha (Kusumaningtyas et al., 2016), papaya seed (Anwar et al., 2019); (iii) syngas from sugarcane bagasse (Daniyanto et al., 2016).

Microalgae emerge as a potential raw material to produce future biofuel resource. Due to its vast utilization, primarily as renewable energy resources, the production of the third generation of biodiesel from microalgae lipid was investigated (Nafis et al., 2015; Suganya et al., 2016). The attractiveness of these microorganisms mainly comes from its features, such as higher productivity and oil content than other energy crops (Saharan et al., 2013). Previous researches found that extraction lipids from microalgae were high energy consumption, which inhibits the industrial-scale production of biodiesel from microalgae to be profitable (Collet et al., 2014). Some researchers attempted to develop the process with low energy extraction consumption. In this context, the hydrodynamic cavitation method for lipid extraction offers the feasibility to perform lipid extraction with lower energy consumption (Yen et al., 2013). This method also gives a fast extraction rate and low energy cell disruption (Setyawan et al., 2018b).

\footnotetext{
* Corresponding Author: abudiman@ugm.ac.id
} 
Citation: Setyawan, M., Mulyono, P., Sutijan, Pradana, Y.S., Prasakti, L., and Budiman, A. (2020). Effect of Devices and Driving Pressures on Energy Requirements and Mass Transfer Coefficient on Microalgae Lipid Extraction Assisted by Hydrodynamic Cavitation. Int. Journal of Renewable Energy Development, 9(3), 467-473, doi:10.14710/ijred.2020.26773

$\mathrm{P}$ a g e 1468

Cavitation events caused the rupture of microalgae cells in extraction by hydrodynamic cavitation. Cavitation occurred due to a decrease in vapor pressure in the fluid flow; this decrease in vapor pressure was caused by an increase in the flow velocity of the liquid. The cavitation generator in this study was designed to generate cavitation by increasing the flow at a point in the flow system in a pipe, giving a narrowing of the flow section. The cavitation event was influenced by the geometry of the cavitation generator and the flow velocity (Carpenter $e t$ al., 2017). In a discrete flow system with an air pressure boost, the magnitude of the driving pressure also affects the cavitation event (Setyawan et al., 2018a).

Although hydrodynamic cavitation was proven to have low energy extraction requirements, efforts to reduce energy demand need to be continuously researched. The energy requirements for extraction in a hydrodynamic cavitation system are influenced by the geometry of the cavitation generator, and the amount of driving pressure. In this research, the influence of the geometry of cavitation generator and driving pressure on the energy requirements have been studied to get the minimum energy requirement, and the volumetric overall mass transfer coefficients of hydrodynamic cavitation lipids extraction have been evaluated.

\section{Materials and Methods}

\subsection{Microalgae}

Dry microalgae Nannochloropsis sp., which was purchased from Balai Budidaya Air Payau in Situbondo East Java, Indonesia, was used as the lipid source. The dry microalgae were delivered in green powder and used as received. The total lipid analysis was done to determine the lipid content in the microalgae.

\subsection{Solvents}

The solvents which were used in this experiment were $n$ hexane and methanol. $N$-hexane industrial grade was purchased from Brataco chemicals (PT. Brataco), Yogyakarta, Indonesia. Methanol industrial grade was purchased from Multi Kimia chemicals (CV. Multi Kimia), Yogyakarta, Indonesia.

\subsection{Equipment}

In the investigation of the effect of cavitation generator geometry, this research was using three shapes of cavitation generator. These shapes were two types of venturi, which were named GC1 and GC2, and the third shape was an orifice, which was called GC3 (Carpenter et al., 2017), as shown in Fig. 1.

All of the three shapes (GC1, GC2, and GC3) had a similar ratio between the pipe cross-sectional area (A1) was $2.125 \mathrm{~cm}^{2}$, and the reduced cross-sectional area (A2) was $0.827 \mathrm{~cm}^{2}$. In addition to that, another variable's difference ratio A1 was $2.125 \mathrm{~cm}^{2}$, and A2 was $1.298 \mathrm{~cm}^{2}$ with the shape of GC1. Table 1 shows the geometry dimension of the three shapes of the cavitation generator.

The experiment was performed by a batch hydrodynamic cavitation using a discrete flow system. The unit was consisted of a compressor, sample chamber, venturi, and product chamber, as shown in Fig. 2.
Table 1

The dimensions of $\mathrm{D}, \mathrm{H}$, and $\mathrm{L}$ of the device for the three shapes

\begin{tabular}{cccc}
\hline Type of Shape & $\mathrm{D}, \mathrm{cm}$ & $\mathrm{H}, \mathrm{cm}$ & $\mathrm{L}, \mathrm{cm}$ \\
\hline GC1 & 1.645 & 0.985 & 1.706 \\
GC2 & 1.645 & 0.571 & 0.989 \\
GC3 & 1.645 & 0.309 & - \\
\hline
\end{tabular}
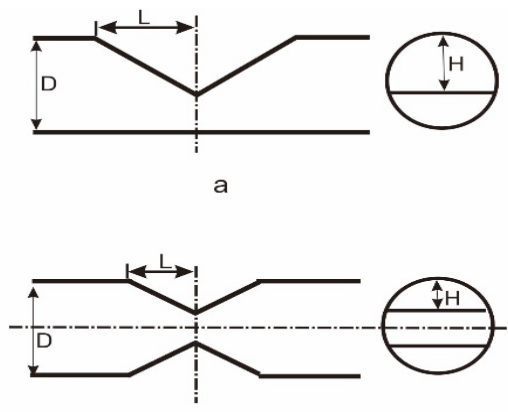

b

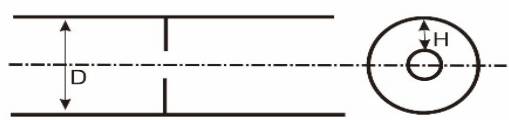

Fig 1. a. Shape 1 (GC1), b. Shape 2 (GC2), c. Shape 3 (GC3)

The compressor supplied compressed air and drove the solvent-sample mixture from the sample chamber to flow through the cavitation generator. The cavitation generator would generate cavitation while the products were collected in the product chamber. Finally, fluid and solid phase products were separated using a centrifuge. The lipid product was obtained by evaporating the solvent from the liquid phase.

\subsection{Experimental Procedures}

\subsubsection{Total Lipids Content}

Experiments to determine the total lipid content were carried out by stirring with a stirring speed of $1000 \mathrm{rpm}$ for 2 hours using solvents a mixture of hexane and methanol with a volume ratio of 2: 1 (Malekzadeh et al., 2016). The extraction was repeated until the extraction yield was close to zero. The extraction results were close to zero, indicating that the lipid content of the microalgae has been depleted.

\subsubsection{Hydrodynamic Cavitation Lipids Extraction (HCLE)}

The experiments of HCLE were performed at $30{ }^{\circ} \mathrm{C}$ with a microalgae concentration of $7.3 \%$ (dry microalgae weight/total feed weight). The first experiment was conducted by varying geometry of the cavitation generator (GC1, GC2, and GC3) and the ratio of A1 \& A2 for GCI geometry type. The second experiment was carried out with variations in the driving pressure of $6.8,5$, and 4.167 bar. A mixture of methanol and hexane (1:2.32 v/v) was used as the extraction solvents. The microalgae and solvents were fed into the chamber and then were flown through the cavitation generator with a specific driving pressure. 


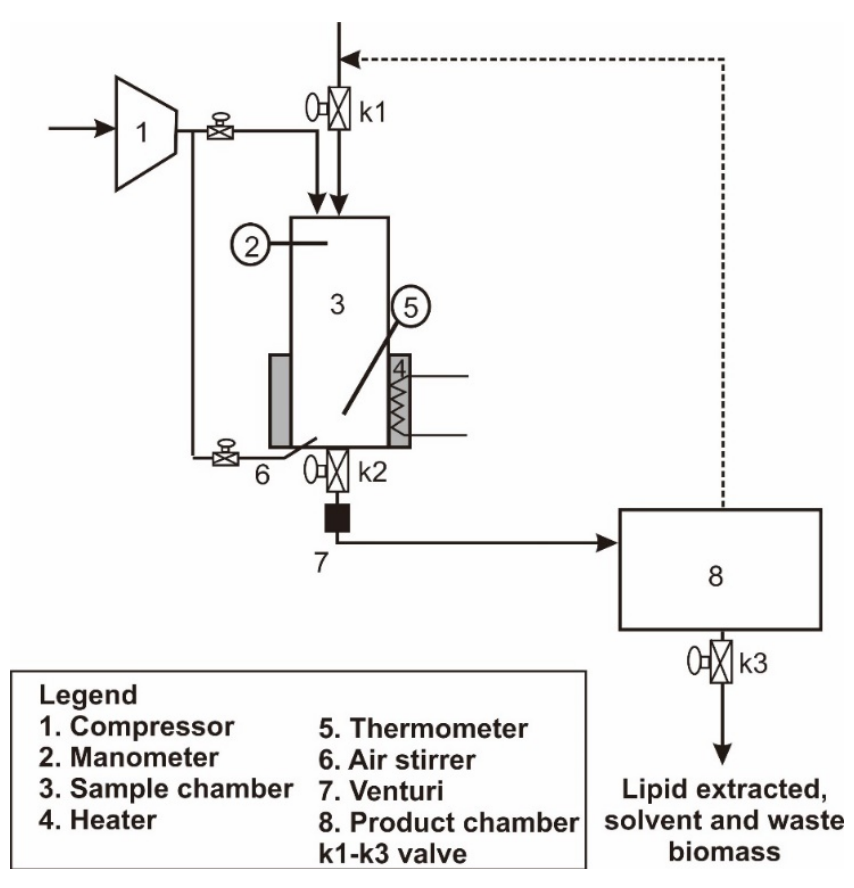

Fig. 2. Hydrodynamic Cavitation Equipment

Once the extraction was completed, to ensure that no lipids were left in the apparatus, after all the material was removed from the apparatus, rinsed it with $10 \mathrm{ml}$ hexane three times until the color of the hexane is clear and colorless. After that, the liquid and solids phase was separated using centrifugation process with a speed of $2000 \mathrm{rpm}$ for 30 minutes. The liquid phase obtained was a mixture of lipids and solvents.

\subsubsection{Conventional Lipid Extraction}

Conventional lipid extraction was carried out by stirring method with a stirring speed of $260 \mathrm{rpm}$. This experiment was carried out at room temperature and using the same solvent and ratio of dry microalgae to the solvent as HCLE investigation. The experiment was carried out with variable extraction time to obtain a time function extraction curve as a comparison for the HCLE process.

\subsubsection{Lipids Separation}

Lipids were separated from the mixture by evaporating the solvents. The evaporation process was carried out to a maximum temperature of $80^{\circ} \mathrm{C}$ and was finished until a fixed non-volatile weight was obtained. After all of the solvents were evaporated, the non-volatile matters were lipids and fine solids. To ensure that all extracted lipids can be taken, the non-volatile matters were weighed ( $\left.\mathrm{w}_{1}\right)$. It was weighed using the analytical balance Ohaus $320 \mathrm{~g}$ x $0.00001 \mathrm{~g}$. After that, the non-volatile matters were washed using $5 \mathrm{ml}$ of hexane (three times), and the remaining solids were dried to achieve a constant weight (w2). The lipids-free solid weight $\left(\mathrm{w}_{\mathrm{p}}\right)$ were obtained from the biomass was calculated using:

$w_{p}=w_{1}-w_{2}$

The extraction yield was defined as the mass ratio of extracted lipid $\left(w_{p}\right)$ to dry microalgae $\left(w_{m i}\right)$ : yield $=\frac{w_{p}}{w_{m i}}$

\subsection{Extraction Energy Requirement}

The HCLE process requires energy to feed the microalgae and solvent through the device for generating the cavitation. The energy requirement was calculated by multiplying the air driving pressure with the crosssectional area of the sample chamber and the sample depth. The energy requirement (E) is calculated using Equation (3):

$E=9.8 P \frac{\pi}{4} D^{2} L$

where $\mathrm{E}$ was the extraction energy requirement (Joule), $\mathrm{P}$, $\mathrm{D}$, and $\mathrm{L}$ were the pressure of the sample chamber $\left(\mathrm{kg} / \mathrm{cm}^{2}\right)$, the diameter of the sample chamber $(\mathrm{cm})$, and the sample depth $(\mathrm{cm})$ respectively. A value of 9.8 was the conversion factor from kgf to Newton. The specific extraction energy requirement $\left(\mathrm{E}_{\mathrm{s}}\right)$ can be calculated using:

$E_{s}=9.8 P \frac{\pi}{4} D^{2} L / w_{p}$

Equation (4) shows the value of specific extraction energy as a function of the volume of the sample and driving pressure.

\subsection{Model and Characteristic of HCLE}

The critical parameter in the extraction equipment design was the mass transfer coefficient. However, lipid extraction involved a mass transfer phenomenon from a large number of microalgae, with the average diameter of $10 \mu \mathrm{m}$, one $\mathrm{kg}$ of dry microalgae was estimated to consist of $3.86 \times 10^{13}$ cells (Lee et al., 2013). Therefore, to evaluate the coefficients of mass transfer, the volumetric overall mass transfer coefficient is preferable. As cell disruption also occurred during hydrodynamic cavitation, the calculations of these coefficients were carried out using two approximations, considering both intact and disrupted microalgae (Sovová, 2005).

In this model, the lipid mass transfer from the disrupted and intact microalgae was taken separately. The changing lipid concentration in the solvent can be written as:

$m_{f} \frac{\partial y}{d t}=j_{f}+j_{s}$

where $j_{f}$ represents lipid mass flux from the disrupted microalgae, $y$ represents lipid concentration in the solvents, $m_{f}$ represents a mass of solvents, and $j_{s}$ represents lipid mass flux from the intact microalgae. The lipid mass flux from disrupted microalgae is a function of the disrupted microalgae fraction and changing lipid concentration in the microalgae and can be written as:

$r m_{s} \frac{d x_{1}}{d t}=-j_{f}$

where $r$ represents the fraction of disrupted microalgae, $x_{1}$ represents lipid concentration in the disrupted 
Citation: Setyawan, M., Mulyono, P., Sutijan, Pradana, Y.S., Prasakti, L., and Budiman, A. (2020). Effect of Devices and Driving Pressures on Energy Requirements and Mass Transfer Coefficient on Microalgae Lipid Extraction Assisted by Hydrodynamic Cavitation. Int. Journal of Renewable Energy Development, 9(3), 467-473, doi:10.14710/ijred.2020.26773

$\mathrm{P}$ a g e 1470

microalgae, and $m_{s}$ represents a mass of dry microalgae. The lipid mass flux from disrupted microalgae can be written as mass transfer equation as follows:

$j_{f}=k_{f} a_{o} \rho_{f}\left(y_{1}^{*}-y\right)$

where $k_{f} a_{o}$ represents a volumetric mass transfer coefficient from disrupted microalgae, $y^{*}{ }_{1}$ was the lipid concentration at the surface of disrupted microalgae. Value of $y^{*}$ is estimated by using Equation 8:

$$
y^{*}=K . x
$$

where $K$ represents equilibrium constant and the value of $\mathrm{K}$ is 0.314 at $32^{\circ} \mathrm{C}$ (Setyawan et al., 2018b).

The lipids mass transfer from intact microalgae can be written as:

$$
(1-r) m_{s} \frac{d x_{2}}{d t}=-j_{S}
$$

where $x_{2}$ represents lipid concentration in the intact microalgae. The lipid mass flux from intact microalgae can be written as:

$j_{s}=k_{s} a_{s} \rho_{f}\left(y_{2}^{*}-y\right)$

where $k_{s} a_{s}$ represents volumetric mass transfer coefficient from intact microalgae and $y^{*}{ }_{2}$ represents lipid concentration at the surface of intact microalgae. The number of lipids released from intact and disrupted microalgae can be evaluated using HCLE and mixing experimental extraction data.

\section{Results and discussion}

Gravimetric analysis of the microalgae showed that the lipids content of Nannochloropsis sp. contained 10.46\% (w/w). GCMS analysis showed that the lipids mainly consisted of $\mathrm{C}_{20} \mathrm{H}_{40} \mathrm{O}, \mathrm{C}_{20} \mathrm{H}_{38}, \mathrm{C}_{17} \mathrm{H}_{34} \mathrm{O}_{2}$, and $\mathrm{C}_{17} \mathrm{H}_{32} \mathrm{O}_{2}$.

\subsection{Effect of cavitation generator geometry}

Fig. 3 shows the effect of cavitation generator geometry on the yield. Geometry GC1 gave the highest yield compared to GC2 and GC3 for all driving pressure values. From Table 1, the ratio of $\mathrm{A} 2$ and $\mathrm{A} 1$ could be calculated, and the value was equal for GC1, GC2, and GC3, which was 0.389. In GC1, there was one concave side with a depth of $0.985 \mathrm{~cm}$. In GC1, the length of the inclined plane was the longest compared to GC2 and GC3. The cavitation would be concentrated in the inclined plane (Cui et al., 2018), so the longer incline plane would cause higher cavitation for the same driving pressure. As a consequence, the cavitation effect of disrupting microalgae was the greatest one.

Fig. 4 shows the effect of the cavitation generator geometry on the specific energy extraction. It was shown that the GC1 geometry gave the lowest specific energy extraction compared to GC2 and GC3 for every driving pressure.

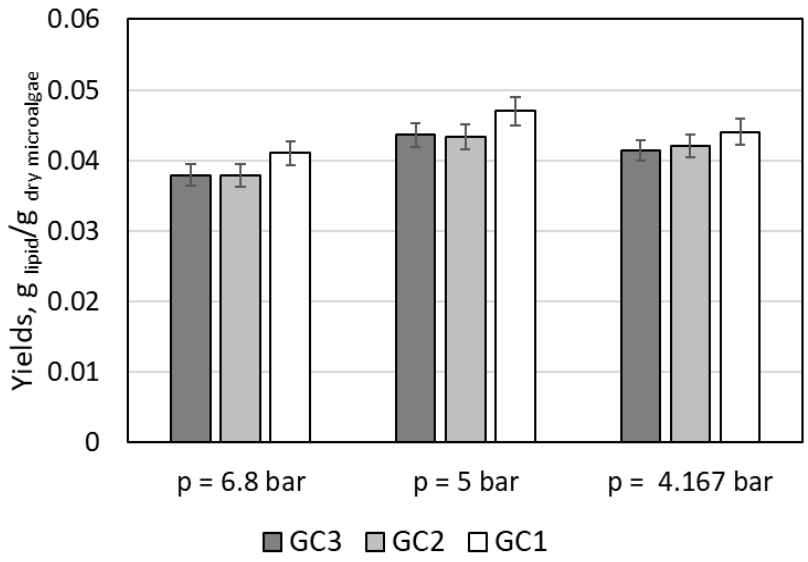

Fig. 3. Effect of cavitation generator geometry and driving pressure on the yields

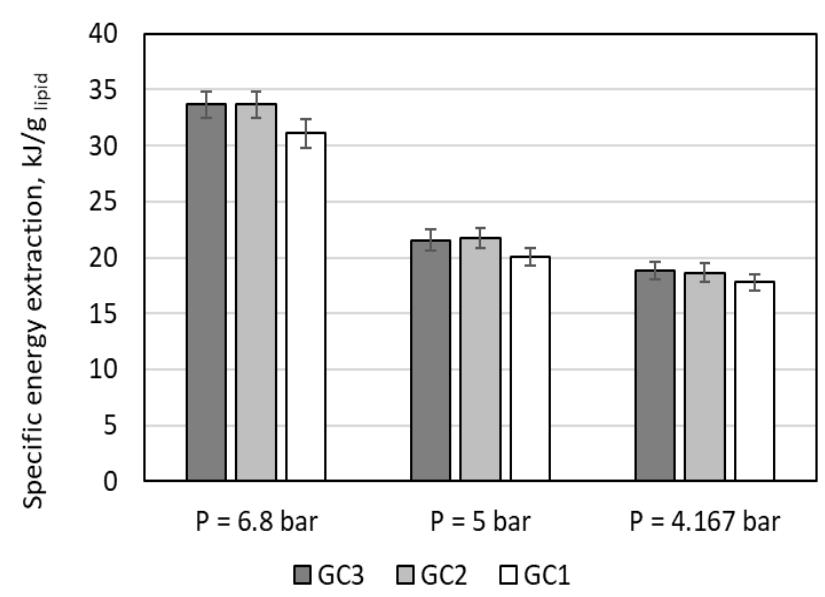

Fig. 4. Effect of cavitation generator geometry and driving pressure on the specific energy of extraction

This result was opposite to the yield of extraction due to the definition of specific energy itself. That was energy, which was used to drive the microalgae and mixture solvent divided by the weight of lipid yielded. The lower specific energy extraction was a more efficient process.

\subsection{Effect of driving pressure}

Driving pressure influenced both fluid velocity and cavitation number (Carpenter et al., 2017). The cavitation number was the parameter to describe the cavitation condition in the cavitation generator. Its value can confirm whether the cavitation occurred. In the case of using venturi and orifice, it can be calculated by using Eq (11):

$$
\sigma_{v}=\frac{P_{\text {downstream }}-P_{v}}{P_{\text {upstream }}-P_{\text {downstream }}}
$$

where $\sigma$ and $P$ were cavitation number and pressure respectively, for flow around a $10-\mathrm{mm}$ circular cylinder, the cavitation inception number was around 1.5 (Franc and Michel, 2005). Cavitation number and energy consumption for the HCLE process can be seen in Table 2 . The amount of energy consumption was calculated using Equation (3). 
Table 2

Cavitation number and energy consumption at different driving pressure

\begin{tabular}{c|cc|}
\hline $\begin{array}{c}\text { Driving pressure, } \\
\text { bar }\end{array}$ & $\begin{array}{c}\text { Cavitation } \\
\text { number }\end{array}$ & Energy, kJ \\
\hline 6.8 & 0.068 & 9.594 \\
5 & 0.1 & 7.055 \\
4.167 & 0.126 & 5.879 \\
\hline
\end{tabular}

Smaller cavitation numbers indicated a greater cavitation phenomenon (Carpenter et al., 2017). However, in this case, the greater cavitation phenomenon did not always result in a high extraction yield. Fig. 3. shows that the highest extraction yield was obtained at the driving pressure 5 bar for all three types of geometry. The interaction between cavitation and microalgae caused this phenomenon. Higher driving pressure resulted in higher speed fluid flow and more significant cavitation, yet it will shorten the contact time. Hence, the optimum interaction would give the best extraction yield. According to Table 2, the amount of energy for the HCLE process was influenced by driving pressure. Fig. 4 presents the effect of driving pressure on the specific extraction energy. The lowest specific extraction energy was achieved at the driving pressure value of 4.167 bar.

\subsection{Effect of the constriction area ratio}

The constriction area ratio produces an influence on the extraction yields, as shown in Fig. 5, which depicts the comparison between the ratio of constriction $\mathrm{r}_{1}=0.61$ and $\mathrm{r}_{2}=0.39$. It showed that the greatest difference in extraction yield due to the constriction area was achieved at a lower driving pressure. This phenomenon occurred because, at the driving pressure of 4.167 bar, the cavitation process between $r_{1}$ and $r_{2}$ was quite different.

On the other hand, increasing driving pressure would equalize the cavitation phenomenon between $r_{1}$ and $r_{2}$. Therefore, the smaller constriction area ratio was recommended to obtain higher extraction yield with a lower driving pressure, which in turn also led to a more efficient extraction energy consumption. The lowest extraction energy requirement that can be reached at the value was $17.79 \mathrm{~kJ}$ oule/g lipids. This value is lower than the energy requirement of other methods of lipids extraction, such as the autoclave method, which needs 380 kJoule/g lipid; ultrasonic methods need 550 kJoule/g lipid (Lee and Han, 2015).

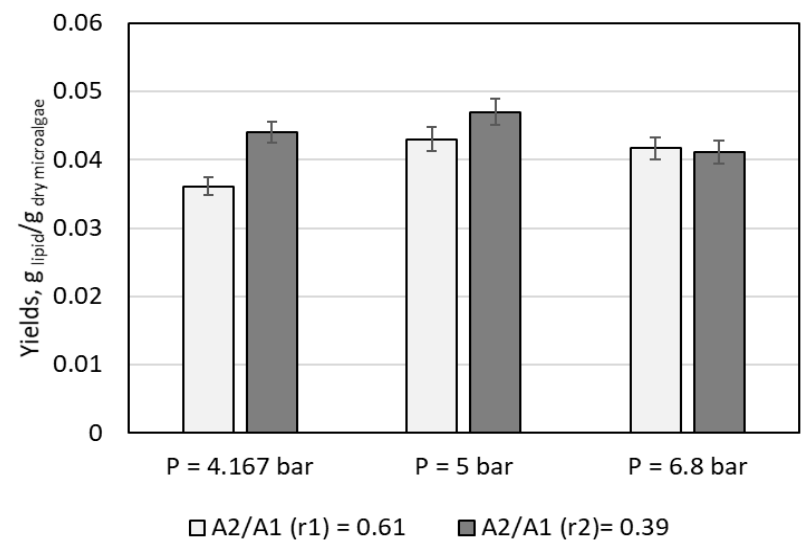

Fig. 5. Effect of the constriction ratio on the extraction yield
This HCLE energy requirement value is less than the biodiesel low heating value, which is around $36.5 \mathrm{~kJ}$ oule $/ \mathrm{g}$ biodiesel (Giakoumis and Sarakatsanis, 2018).

\subsection{Volumetric mass transfer coefficient evaluation}

The experimental data and results of the simulation model are shown in Fig. 6. It was shown that the extraction yields in the HCLE process were higher than conventional extraction. It was indicated the difference in extraction rate between HCLE and conventional extraction. It also indicated a difference extraction rate in HCLE as a function of time of extraction.

The comparison between HCLE and conventional extraction, it appears that the HCLE extraction rate is greater than conventional extraction. This was caused by a different mechanism of the lipid release from microalgae to the solvent. In the HCLE, there were lipids released from intact and disrupted microalgae simultaneously (Yamamoto et al., 2015). Meanwhile, in the conventional extraction, the lipids were only released from the intact microalgae.

From Fig. 6, it can be observed that there were two sections of the extraction curve in the HCLE. It was shown by the difference slope of the extraction curve. In the first minute, the HCLE process gives a large yield, which is above $0.04 \mathrm{~g}$ lipid / g dry microalgae for one time (1 minute), it was done at one pass cavitation. In the next section, there was a decrease in the extraction yield, which was obtained in a range of 0.014 to $0.008 \mathrm{~g}$ lipid / g dry microalgae for 5 passes (five minutes), or around 0.0027 to $0.0015 \mathrm{~g}$ lipid / g dry microalgae per minute. This shows that the cavitation event did not significantly increase the extraction yield. The cause of this phenomenon was that the cavitation event did not disrupt microalgae as much as in the first section for the broken and intact microalgae are randomly mixed. Once the cavitation hit, the broken microalgae did not affect the extraction yield. Therefore, the highest cavitation effect on the HCLE was at the beginning process. Mathematical models were evaluated with assumptions that in the disrupted microalgae, all lipids were completely released when the cell wall was ruptured. Based on Fig. 6, the number of microalgae disrupted fraction and lipids released from intact and disrupted microalgae were obtained.

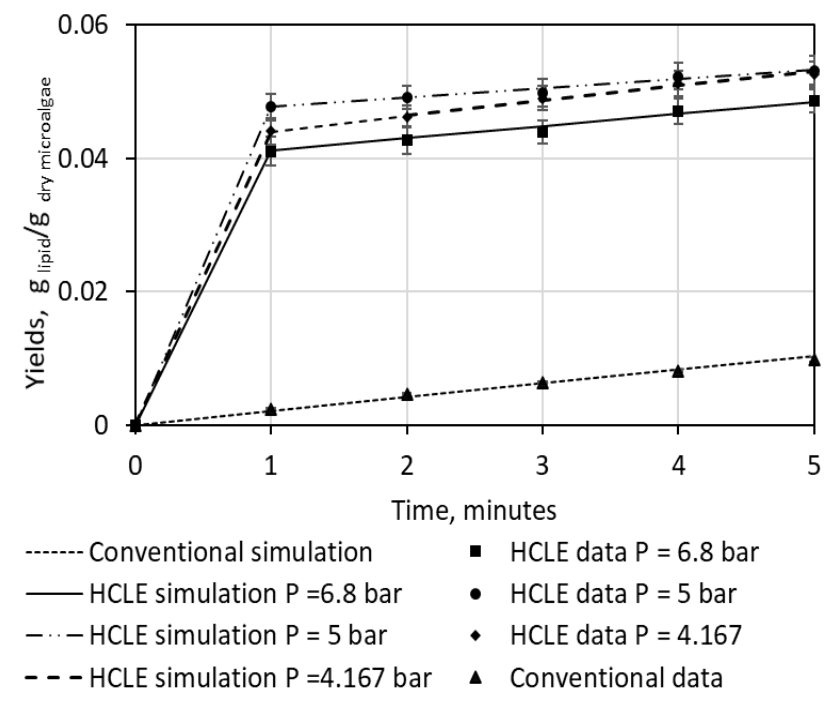

Fig. 6. HCLE and mixing extraction experimental data and simulation result 
Citation: Setyawan, M., Mulyono, P., Sutijan, Pradana, Y.S., Prasakti, L., and Budiman, A. (2020). Effect of Devices and Driving Pressures on Energy Requirements and Mass Transfer Coefficient on Microalgae Lipid Extraction Assisted by Hydrodynamic Cavitation. Int. Journal of Renewable Energy Development, 9(3), 467-473, doi:10.14710/ijred.2020.26773 $\mathrm{P}$ a g e 1472

Table 3

Value of the $k_{f} a_{o}$ for a various driving pressure

\begin{tabular}{cccc}
\hline \multirow{2}{*}{$\begin{array}{c}\text { Driving pressure, } \\
\text { bar }\end{array}$} & \multicolumn{2}{c}{$k_{f} a_{o}, 1 /$ minute } & \multirow{2}{*}{$\mathrm{R}^{2}$} \\
\cline { 2 - 3 } 6.8 & Section 1 & Section 2 & \\
5 & 2.021 & 0.127 & 0.971 \\
4.167 & 2.456 & 0.105 & 0.964 \\
\hline
\end{tabular}

Those data will then allowed the calculation of $k_{f} a_{o}$ and $k_{s} a_{s}$ to proceed. The result of the proposed model is plotted in Fig. 6, while the values of $k_{f} a_{o}$ are presented in Table 3 . The values of $k_{s} a_{s}$ for all driving pressure values were equal to the conventional extraction process: 0.086 $1 /$ minute

The value of $k_{f} a_{o}$ in the first section was 20 times fold larger than the lipids released from the intact microalgae (conventional extraction). Those results implied that the lipid release from broken microalgae was dominant in the process. In the second section, the value of $k_{f} a_{o}$ was only 1.22 to 1.94 times fold larger than from intact microalgae. It showed that the amount of microalgae disruption tends to decrease. Thus the characteristic of HCLE was represented in the first section.

Comparison of the value of the volumetric mass transfer coefficient between HCLE methods and conventional method, which was the value of the HCLE methods larger than Conventional method almost 20 times fold, that indicate the HCLE proses is more effective.

\section{Conclusion}

The experiment results showed that in the HCLE process, both the cavitation generator geometry and driving pressure had an effect on extraction yields and specific extraction energy. The effect of cavitation generator geometry revealed that shape 1 (GC1) gave the highest extraction yield at a constant driving pressure, microalgae concentration $\left(\mathrm{C}_{\mathrm{m}}\right)$, and temperature $(\mathrm{T})$. The effect of the driving pressure at 5 bar produces the highest extraction yield for all shapes of cavitation generator geometry, microalgae concentration, and temperature. The lipids yield at $\mathrm{T}=30^{\circ} \mathrm{C}$ and $\mathrm{C}_{\mathrm{m}}=7.3 \%$ dry microalgae weight/total feed weight was $4.7 \% \mathrm{~g}$ lipid/g dry microalgae, which was equal to $44.93 \%$ of total lipids Moreover, the lowest value of $\mathrm{E}_{\mathrm{s}}$ was able to be achieved by using GC1 and the driving pressure at 4.167 bar. The value of the energy extraction requirement at the condition of $30{ }^{\circ} \mathrm{C}$ and $\mathrm{C}_{\mathrm{m}}$ of $7.3 \%$ dry microalgae weight/total feed weight was $17.79 \mathrm{~kJ} / \mathrm{g}$ lipids, this value less than biodiesel heating value. The value of the volumetric mass transfer coefficient of the HCLE method is almost 20 times fold larger than conventional extraction methods, therefore this method is more efficient and promising to be further developed.

\section{Acknowledgments}

We would like to thank Universitas Gadjah Mada for research and publication funding. We also gratefully acknowledge the partial funding from Ahmad Dahlan University, Yogyakarta, Indonesia.

\section{References}

Anwar, M., Rasul, M.G., Ashwath, N., \& Nabi, M.D.N. (2019). The potential of utilizing papaya seed oil and stone fruit kernel oil as non-edible feedstock for biodiesel production in Australia-A review. Energy Reports, 5, 280-297; doi: 10.1016/j.egyr.2019.02.007

Budiman, A., Ishida, M., (1996). Three-dimensional graphical exergy analysis of a distillation column. Journal Chem. Eng. Japan, 29(4), 662-668; doi:10.1252/jcej.29.662

Carpenter, J., George, S., Saharan, V.K., (2017). Low pressure hydrodynamic cavitating device of producing highly stable oil in water emulsion: Effect of geometry and cavitation number. Chem. Eng. Process. Process Intensif. 116, 97-104. doi: 10.1016/j.cep.2017.02.013

Collet, P., Lardon, L., Hélias, A., Bricout, S., Lombaert-Valot, I., Perrier, B., Lépine, O., Steyer, J.-P., Bernard, O., (2014). Biodiesel from microalgae-Life cycle assessment and recommendations for potential improvements. Renew. Energy 71, 525-533. doi: 10.1016/j.renene.2014.06.009

Cui, J., Lai, H., Feng, K., Ma, Y., (2018). Quantitative analysis of the minor deviations in nozzle internal geometry effect on the cavitating flow. Experimental Therm. Fluid Sci. 94, 8998. doi: 10.1016/j.expthermflusci.2018.02.002

Daniyanto, Sutijan, Deendarlianto, Budiman, A., (2016). Reaction kinetic of pyrolysis in mechanism of pyrolysis gasification process of dry torrified sugarcane bagasse. ARPN J. Eng. Appl. Sci. 11(16), 9974-9980.

Franc, J.-P., Michel, J.-M., 2005. Fundamentals of Cavitation. Kluwer Academic Publishers, New York.

Giakoumis, E.G., Sarakatsanis, C.K., (2018). Estimation of biodiesel cetane number, density, kinematic viscosity and heating values from its fatty acid weight composition. Fuel 222, 574-585; doi: 10.1016/j.fuel.2018.02.187

Jamilatun, S., Yuliestyan, A., Hadiyanto, H., (2019). Comparative Analysis Between Pyrolysis Products of Spirulina platensis Biomass and Its Residues, Int. Journal of Renewable Energy Development, 8(2),133-140; doi: 10.14710/ ijred.8.2.133-140

Kusumaningtyas, R.D., Aji, I.N., Hadiyanto, H., Budiman, A., (2016). Application of tin (II) chloride catalyst for high FFA Jatropha oil esterification in continuous reactive distillation column. Bull. Chem. React. Eng. Catal. 11, 66; doi: $10.9767 / \mathrm{bcrec} .11 .1 .417 .66-74$

Lee, A.K., Lewis, D.M., Ashman, P.J., (2013). Force and energy requirement for microalgal cell disruption: An atomic force microscope evaluation. Bioresour. Technol. 128, 199-206. doi:10.1016/j.biortech.2012.10.032

Lee, I., Han, J.I., (2015). Simultaneous treatment (cell disruption and lipid extraction) of wet microalgae using hydrodynamic cavitation for enhancing the lipid yield. Bioresour. Technol. 186, 246-251. doi: 10.1016/j.biortech.2015.03.045

Malekzadeh, M., Abedini Najafabadi, H., Hakim, M., Feilizadeh, M., Vossoughi, M., Rashtchian, D., (2016). Experimental study and thermodynamic modeling for determining the effect of non-polar solvent (hexane)/polar solvent (methanol) ratio and moisture content on the lipid extraction efficiency from Chlorella vulgaris. Bioresour. Technol. 201, 304-311. doi: 10.1016/j.biortech.2015.11.066

Nafis, G.A., Mumpuni, P.Y., Indarto, Budiman, A., (2015). Combination pulsed electric field with ethanol solvent for Nannochloropsis sp. extraction. AIP Conf. Proc. 1699. doi:10.1063/1.4938306

Pradana, Y.S., Azmi, F.A., Masruri, W., Hartono, M., (2018). Biodiesel production from wet spirulina sp. By one-step extraction-transesterification. MATEC Web of Conferences. 156, 03009, 1-4; doi.org/10.1051/matecconf/201815603009

Pradana, Y.S., Sudibyo, H., Suyono, E.A., Indarto, Budiman, A., (2017). Oil algae extraction of selected microalgae species grown in monoculture and mixed cultures for biodiesel production. Energy Procedia, 105, 277-282; doi: 10.1016/j.egypro.2017.03.314

Saharan, B.S., Sharma, D., Sahu, R., Sahin, O., (2013). Towards algal biofuel production: a concept of green bio energy 
development. Innov. Rom. Food Biotechnol. 12, 1-21.

Sawitri, D.R., Sutijan, Budiman, A., (2016). Kinetics study of free fatty acids esterification for biodiesel production from palm fatty acid distillate catalysed by sulphated zirconia. ARPN J. Eng. Appl. Sci. 11(16), 9951-9957.

Setyawan, M., Budiman, A., Mulyono, P., Sutijan, (2018a). Optimum extraction of algae-oil from microalgae using hydrodynamic cavitation. Int. J. Renew. Energy Res. 8(1), 451-458.

Setyawan, M., Mulyono, P., Sutijan, Budiman, A., (2018b). Comparison of Nannochloropsis sp . cells disruption between hydrodynamic cavitation and conventional extraction. MATEC Web of Conferences. 154(01023), 1-5. doi: 10.1051/matecconf/201815401023

Soulayman, S., Ola, D., (2019). Synthesis Parameters of Biodiesel From Frying Oils Wastes. Int. Journal of Renewable Energy Development, 8(1),33-39; doi:10.14710/ijred.8.1.33-39

Sovová, H., (2005). Mathematical model for supercritical fluid extraction of natural products and extraction curve evaluation. J. Supercrit. Fluids 33, 35-52. doi: 10.1016/j.supflu.2004.03.005

Sudibyo, H., Pradana, Y.S., Samudra, T.T., Budiman, A., Indarto, Suyono, E.A., (2017). Study of cultivation under different colors of light and growth kinetic study of Chlorella zofingiensis Dönz for biofuel production. Energy Procedia 105, 270-276; doi: 10.1016/j.egypro.2017.03.313

Suganya, T., Varman, M., Masjuki, H.H., Renganathan, S., (2016). Macroalgae and microalgae as a potential source for commercial applications along with biofuels production: A biorefinery approach. Renew. Sustain. Energy Rev. 55, 909-941. doi: 10.1016/j.rser.2015.11.026

Sunarno, Rochmadi, Mulyono, P., Aziz, M., Budiman, A., (2018). Kinetic study of catalytic cracking of bio-oil over silicaalumina catalyst. BioResources 13, 1917-1929. doi: 10.15376/biores.13.1.1917-1929

Wicakso, D.R., Hidayat, M., Cahyono, R.B., (2018). Effect of temperature on catalytic decomposition of tar using Indonesian iron ore as catalyst. Int. J. Renew. Energy Res. 8(1), 421-427..

Yamamoto, K., King, P.M., Wu, X., Mason, T.J., Joyce, E.M., (2015). Effect of ultrasonic frequency and power on the disruption of algal cells. Ultrason. Sonochem. 24, 165-171. doi: 10.1016/j.ultsonch.2014.11.002

Yen, H., Hu, I., Chen, C., Ho, S., Lee, D., Chang, J., (2013). Microalgae-based biorefinery - From biofuels to natural products. Bioresour. Technol. 135, 166-174. doi: 10.1016/j.biortech.2012.10.099 